\title{
O conflito Israel/Palestina como acontecimento jornalístico: análises de narrativas do jornal Folha da Manhã (1936/1946)
}

\author{
Fernando Antônio Resende \\ Letícia Rossignoli
}

Resumo: Este artigo apresenta análises de narrativas do jornal Folha da Manhã (1936/1946) sobre o conflito Israel/Palestina. As discussões que o move gravitam em torno das relações de poder inscritas no conflito, buscando entender os modos que as narrativas jornalísticas encenam as lutas por hegemonias, dando a ver o processo de produção de sentidos no território palestino. Na medida em que o significante terrorismo, nestas narrativas do início do século XX, desliza e se cola nos sujeitos que interessam ao poder, o que se nota é a participação efetiva do jornalismo em processos nos quais estão imbricados as práticas e os gestos políticos, culturais e discursivos de inclusão e exclusão de sujeitos. Desse modo, ao entender o jornalismo como uma prática cultural discursiva, este artigo também se propõe a refletir sobre os modos de produção daquilo que se entende como acontecimento jornalístico.

Palavras-chave: jornalismo; jornal Folha da Manhã; narrativas; acontecimento.

Abstract: The Israeli Palestine conflict as a journalistic event: some analyses of narratives from the newspaper Folha da Manhã (1936/1946) - This article presents some analyses of narratives from the newspaper Folha da Manhã (1936/1946) about the conflict between Israel and Palestine. The discussions it drives orbit around the power relations inscribed in the conflict, so to comprehend the ways journalistic narratives shed light on those disputes for hegemony, by showing the process of meaning production in the Palestinian territory. As the signifier "terrorism", in those narratives of the beginning of the 20th century, displaces and attaches itself to subjects who are interesting for those in power, it gets conspicuous the effective participation of the journalism in processes in which political, cultural and discursive gestures and practices of inclusion and exclusion of subjects are imbricated. Thus, by understanding 
journalism as a discursive social practice, this article also proposes a reflection on the ways of producing that we have perceived as a journalistic event.

Keywords: journalism; Folha da Manhã; narratives; event.

Este artigo propõe uma reflexão sobre a representação midiática do conflito Israel/ Palestina em jornais brasileiros. A ideia é discutir como as relações de poder inscritas no conflito tornam-se mais evidentes na medida em que as narrativas jornalísticas colocam em cena as lutas por hegemonias. É nesse instante que o conflito deixa de ser somente o conteúdo da narrativa, passando também a dar forma aos modos de que dele se fala.

No caso Israel/Palestina, particularmente, toda a análise aqui exposta torna muito evidente como a disputa pela narrativa mais verdadeira acerca do conflito coloca em cena a disputa das vozes e dos sentidos. O recorte apresentado neste artigo tem um viés histórico, pois serão apresentadas análises de narrativas da primeira metade do século XX que foram publicadas no jornal Folha da Manhã'.

A materialidade geopolítica inscrita nas narrativas jornalísticas aqui discutidas o território ocupado da Palestina - é dado crucial, na medida em que ali são travadas lutas entre geografias culturais apartadas por regimes políticos, crenças e modos de vida a priori dados como díspares. Pontuaremos os modos contraditórios de apreensão e produção de sentido acerca de significantes, como terrorismo, por exemplo, e as leituras, muitas vezes incoerentes, que as narrativas jornalísticas no Brasil suscitam em torno do conflito árabeisraelense. Trazer tais inferências possibilitam confirmar o jornalismo, pelo menos desde o século XIX, como um importante agente que contribui para a reiteração de um imaginário de caráter etnocêntrico, marcando identidades, diferenças culturais e caminhos através dos quais o jornalismo no Brasil tem produzido sentidos sobre a luta no território palestino.

Um outro aspecto relevante se refere à abordagem pela via da narrativa. Em um espaço geográfico no qual os sujeitos que o habitam experimentam o dilema de ter sido o que hoje não é ou de ter vivido onde hoje não se pode viver, as histórias adquirem um papel crucial: elas se tornam algo entre o esforço de recuperação/sustentação da memória e a própria construção do sentido da terra. Nesse aspecto, o território palestino é, cada vez mais, aquilo que dele se narra (SAID, 2011).

Ao estendermos o espaço geográfico no qual se inscreve o território palestino o Oriente Médio - nós nos deparamos, invariavelmente, com a relação intrínseca que ali existe entre narração e conflito. Matar \& Harb (2013), ao discutirem este aspecto, chamam atenção para o fato de que "em nenhum outro lugar a disputa pela imaginação, construção e narração de conflito, assim como seus sentidos e centralidade no cotidiano das pessoas, é mais contundente", já que no Oriente Médio estas são disputas que,

1 Em julho de 1925 foi criado o jornal Folha da Manhã. Instalado na cidade de São Paulo e endereçado à classe média, o Folha da Manhã teve significativa influência na região sudeste do Brasil. A escolha por esse jornal se deu pela grande quantidade de matérias advindas das agências internacionais que ali eram publicadas. Desse modo, as matérias analisadas fazem parte de um corpus mais amplo que contêm 410 matérias, dentre as quais, 65, são do Jornal do Brasil. 
além de tudo, colocam em questão noções de "espaço, identidade, discurso, imagem, narrativa" (2013, p.4 - tradução livre).

Este modo de abordar o problema, no âmbito geral da pesquisa, se tornou preponderante, pois deu lugar a uma indagação mais precisa em torno do que significa narrar tal geografia. Nas narrativas acerca deste conflito, de forma muito marcante, a disputa pela fala verdadeira se traveste, ela mesma, na guerra pela narrativa: quem narra melhor (ou de forma mais legítima) a chamada ocupação do território, para uns, ou o resgate da Terra Prometida, para outros?

A pesquisa evidencia que a busca pelo verdadeiro é menos relevante do que o escavamento do processo em que se inscrevem as lutas (e possivelmente as verdades) que se escondem atrás dos poderes que engendram e narram o conflito. Aspecto que se colocou de forma ainda mais contundente em se tratando de conflitos de longa duração, já que são tomados por inúmeras camadas de narrativas, gestam variadas histórias e múltiplos sentidos ${ }^{2}$.

Parte do empreendimento desta reflexão é acentuar o pacto entre os grandes conglomerados de comunicação e a lógica do poder instituído, o que nos permite discutir como o conflito Israel/Palestina é construído enquanto acontecimento jornalístico. Um jornalismo aqui entendido, antes de tudo, como prática cultural discursiva, uma práxis tomada por um "conjunto de problemas, orientações, intenções e dizeres que, de forma inseparável, dá a ver o possível do mundo" (RESENDE, 2011, p. 128).

\section{Nuances do conflito}

Alguns estudos apontam como início do conflito entre palestinos e judeus na Palestina a década de 1890, após a fundação do Sionismo. De acordo com Finkelstein (2005), havia um consenso ideológico do qual brotou a maior parte do pensamento doutrinário desse grupo. Neste consenso estava a crença sionista de que a Palestina deveria um dia abrigar uma maioria judaica. Por meio desse pensamento, advém parte das raízes do conflito com os palestinos, que constituía a maioria da população na Palestina há séculos.

Em face da resistência dos palestinos, os sionistas perceberam que para se estabelecerem na região precisariam da proteção de uma força que não dependesse da população local. Para o líder sionista Jabotinsky era necessário uma "muralha de ferro que ela [a população palestina] não seja capaz de romper." (JABOTINSKY apud FINKELSTEIN, 2005, p. 72).

A partir desta estratégia política o movimento sionista buscou aliança com a grande potência que havia na Palestina - a Inglaterra; para conseguir apoio, os sionistas teriam que ceder às suas intenções. Dessa forma, em resposta aos interesses britânicos, o sionismo

2 Irit Rogoff (2000) entende como conflitos de longa duração aqueles que acontecem nos espaços geográficos do Oriente Médio. Para esta autora, eles demandam uma reflexão que reconheça, antes de tudo, o esgotamento dos aparatos epistemológicos e dos recursos analíticos que até então têm amparado os gestos explicativos em torno dos conflitos. Esta é uma abordagem fundamental, não só para este artigo, mas também para a pesquisa como um todo. 
ajudaria a abafar o agravamento do conflito entre os turcos otomanos e os árabes no início do século XX, servindo como cabeça de ponte imperial numa região estrategicamente importante, mas politicamente volátil. O sionismo, também, podia funcionar como pararaios ante o descontentamento popular local, desviando a atenção da potência imperial.

O que apresentamos nesse artigo é como as agências internacionais de notícias, que foram cruciais para o desenvolvimento do noticiário internacional nos jornais brasileiros, serviam de porta-vozes ao ajudar a tecer as disputas de poder no território palestino. É interessante notar que todas as agências que forneciam notícias para o jornal Folha da Manhã sobre o conflito árabe-israelense na primeira metade do século XX estavam localizadas nos Estados Unidos e na Europa ${ }^{3}$. Desse modo, através das agências, as notícias publicadas reiteravam, de forma substancial, os contextos hegemônicos, tanto políticos como econômicos da época. Assim, "a história do jornalismo internacional é de algum modo a história dos vencedores" (NATALI, 2004, p.32).

Portanto, o que este artigo põe em relevo é a clara pactuação existente entre os grandes conglomerados de comunicação e o poderio britânico no que tange à narração dos acontecimentos nessa região. Para entendermos os jogos de poder inscritos nas narrativas iremos focar no uso da palavra terrorista contido no corpus da pesquisa. A mobilidade do termo, ora designada aos árabes, ora aos judeus, irá mostrar como o jornalismo das agências internacionais mostraram sua parcialidade diante do conflito. Para isso, iremos nos ater às notícias publicadas a partir de 1936. Até este ano, poucas eram as matérias que tratavam do conflito árabe-israelense na Palestina. E até esta data as notícias davam destaque para o embate entre judeus e palestinos de modo maniqueísta enaltecendo a intolerância religiosa como a explicação totalizadora do conflito.

Com a instauração da Greve Geral (1936-1939) por parte dos palestinos o jornal mudou o modo de narrar o conflito na região. O Folha da Manhã passou a narrar a insatisfação dos palestinos tanto com o aumento da imigração judaica, como também com o mandato britânico. Houve um aumento no número de notícias publicadas, outros sujeitos históricos foram relatados e os atos violentos ocorridos na Palestina começaram a ser narrados pela insígnia do terror. Palavras como atentado, terrorismo e terrorista passam a aparecer nas narrativas jornalísticas desse tempo.

No que tange à construção da representação dos ingleses no conflito instaurado na Palestina, a partir de 1933 a Grã-Bretanha começa a ter maior participação nas notícias. Isso se deve ao advento do Nacionalismo Árabe que tinha como premissa central que os povos do mundo árabe, desde o Oceano Atlântico ao Mar Arábico, constituíssem uma só nação unida por patrimônio linguístico, cultural e histórico comum.

Como explica Vicenzi (2007) foram os fatores tais como o estabelecimento de mandatos britânicos e franceses no Oriente, após a queda do Império Otomano,

3 As agências que aparecem nessa pesquisa são: a extinta Havas com sede na França, Reuters em Londres e Associated Press nos Estados Unidos. 
a imigração judia e a venda de terra a judeus na Palestina, que moveram os diversos povos árabes, de forma pontual e desconexa, em busca de uma unidade política.

Desse modo, iremos primeiramente mostrar como a palavra terrorista aparece pela primeira vez em meio aos relatos de fatos violentos na Palestina. Nesse momento, será analisado o uso da estratégia textual do não-dito como forma de correlacionar árabes com o termo terrorista usado pelo jornal. Atrelado a isso, daremos enfoque ao tratamento discursivo dado aos atos de resistência por parte dos palestinos pelo jornal. E em seguida, na década de 1940, apontaremos o deslizamento do termo terrorista designado não mais aos árabes, mas, nesse momento, aos judeus.

\section{O que (não) se diz, o que se entende}

Em face do aumento populacional dos judeus e da não intervenção dos ingleses nas políticas de imigração da região, a população árabe iniciou atos públicos de resistência. A matéria datada de 19 de maio de 1936 relata a implantação de uma greve geral por parte dos palestinos. Tal posicionamento de resistência desagrada o poder instituído. A matéria narra que os palestinos iriam continuar com seus atos de resistência. Vejamos:

A situação entre os elementos árabes e israelitas da cidade santa continua muito tensa. A ordem de recolher foi estendida à cidade Alta. Os árabes recusaram sugestão no sentido de ser enviada a Londres uma delegação árabe e de ser nomeada uma comissão imperial britânica encarregada de proceder inquérito sobre o problema da imigração israelista. Os árabes recusam-se a entrar em negociações enquanto não for sustentada a referida immigração. A campanha de desobediência civil e da greve geral continua em vigor. (Considerados de extraordinária gravidade os últimos acontecimentos na Palestina - Folha da Manhã - 19/05/1936).

Interessante observar que toda a trama do conflito se dá na Palestina e por seus civis - neste caso sendo nomeados como árabes. A estratégia narrativa que aqui se apresenta é sutil, os civis palestinos ganham já uma designação homogeneizante: ser árabe é o elemento que os aglutina. Este é um aspecto importante nas narrativas analisadas na pesquisa, pois já neste momento inicial do conflito, o que se nota é a simplificação de um componente identitário relevante no processo de compreensão do que é e a quem pertence o território que estava já em vias de ocupação ${ }^{4}$.

A respeito disso, não podemos esquecer que o Nacionalismo Árabe conclamava, nesse mesmo momento, a união de todos os povos numa vasta região do Oriente a serem uma só nação árabe. A não distinção, portanto, dos civis da Palestina enquanto palestinos

4 Edward Said, especificamente em A questão da Palestina, mas também em várias de suas obras, é contundente na reiteração das diversidades e identidades que marcam as diferenças no espaço do chamado mundo árabe. E o autor é, ao mesmo tempo, bastante crítico em relação ao esforço de construção de uma hegemonia de viés nacionalista que visa à produção de um imaginário homogêneo em torno do que é ser árabe. 
pode também encontrar respaldo na ideologia do Nacionalismo Árabe que, de um modo ou outro, permeava a forma como eram narrados os acontecimentos.

Outra matéria, datada de 13 de junho de 1936, narra a insatisfação dos palestinos com o governo britânico na Terra Santa: "A animosidade de parte dos árabes já não é tanto contra os judeus, como contra a administração britânica e sua campanha racial e religiosa ameaça transformar-se em uma espécie de guerra de independência." (Continua grave a situação na Palestina - Folha da Manhã - 13/06/1936).

Fica claro que havia um confronto ideológico e político entre palestinos e ingleses e que os primeiros estavam reivindicando a independência ante o mandato britânico na Palestina e a paralisação da imigração judaica.

Diante disso, os palestinos reagiram com estratégias de embargo comercial, protestos em lugares públicos e, posteriormente, ataques violentos aos britânicos e judeus; e foram considerados desobedientes civis, num primeiro momento. Passado, aproximadamente, um mês, o discurso feito pelo jornal se referia aos palestinos como (árabes) terroristas.

Esse uso, digamos inicial, da palavra terrorista durante a primeira metade do século XX foi na matéria Continuam as violências na Palestina (Folha da Manhã - 3/07/1936). Nesta matéria o uso do vocábulo terrorista se estabelece discursivamente através do não-dito e, portanto, de modo não explícito vem a se referir aos povos árabes, isto é, aos palestinos. Vejamos:

Os últimos julgamentos exerceram alguma influência sobre as massas árabes, mas, apesar disso, as violências têm continuado. A polícia conseguiu prender grande número de terroristas enviados para o campo de concentração de Serranand, onde já se encontravam 150, dos quais uma parte resolveu fazer greve de fome. Os dirigentes árabes desmentem que a greve dos comerciantes deva acabar no fim de semana. (Continuam as violências na Palestina - Folha da Manhã 3/07/1936 - grifo nosso).

O contexto da notícia gravita em torno da repressão por parte da polícia britânica em face das manifestações realizadas pelos palestinos. A narração das violências ocorridas na Palestina não são claras. Ao que tudo indica, apesar de não se estabelecer uma clara relação entre eles, são aos palestinos que se referem quando mencionados os terroristas e as massas árabes.

Outra matéria, datada de 28 de maio de 1936, exemplifica bem o que Orlandi (2007) trata como o dito e o não-dito. O relato começa dizendo: "[...] na manhã de ontem foram lançadas bombas e trocados tiros em Jaffa sem que houvesse nenhum ferido". Em seguida a narrativa se constrói sobre outro fato que é a proteção pela guarda britânica de judeus austríacos contra os ataques árabes.

O pressuposto, então, é que os árabes vinham atacando os judeus austríacos na Palestina. Logo após essa informação, os relatos sobre os atentados do dia anterior são retomados, sendo descritos os atos de violência. Vejamos: 
[...] durante o dia e a noite de ontem, foram de natureza esporádica: ataque a um automóvel da polícia, descoberta de um carregamento de explosivos, explosões de algumas bombas em Tulkarem, Nazareth [...] (Perdura a animosidade entre árabes e judeus na Palestina - Folha da Manhã - 28/05/1936).

Em nenhum momento, no discurso, faz-se referência a quem teria efetuado os atos de violência narrados na reportagem. Quem teria lançado bombas e trocado tiros em Jaffa? Quem teria atacado um automóvel da polícia? E de quem era o carregamento de explosivos, como também, as bombas lançadas em Tulkarem, Nazaré? Há um silêncio. É dito, porém, que a guarda britânica foi acionada para proteger os judeus austríacos contra ataques dos árabes. E, no final da reportagem, é relatado o pedido de desculpa por parte de autoridades das cidades árabes vizinhas à colônia judia pelos ataques árabes efetuados contra os judeus naquela região.

Passados dois anos, ainda encontramos notícias usando a alcunha terroristas por meio do não-dito. Como podemos ver na reportagem Volta a agravar-se a situação na Palestina (8/07/1938), que noticia situações de violência: "[...] Um patrulhamento de policiais surpreendeu ontem um bando de terroristas com quem travou combate. Nove rebeldes morreram". Novamente, o bando de terroristas e rebeldes não é identificado, mas é inevitável a relação direta com os que já vêm sendo chamados de "árabes".

De acordo com Orlandi, nas construções narrativas, o que é dito tem relação com o não dizer (não dito, mas presente): "[...] sabe-se por aí que, ao longo do dizer, há toda uma margem de não-ditos que também significam" (2007, p.82). Portanto, o dito traz consigo um pressuposto que não está materializado na narrativa, mas impregna a mesma com sua presença.

Grosso modo, os palestinos são relacionados, nas narrativas, a ataques contra judeus. E em meio à miscelânea de informações sobre variados ataques, fica subtendido que são os palestinos os autores das cenas de violência descritas. O jornal não os imputa a responsabilidade sobre os atentados na Palestina, mas, ao não dizer, deram pistas aos leitores de quem seria a autoria dos atentados.

Acrescentado a isso, observamos que os atos violentos deferidos pelos movimentos de resistência eram relatados com certo tom de descaso. A impressão de quem lê as notícias é que as ações eram realizadas de forma aleatória e gratuita, como se não houvesse por parte dos palestinos motivos para promover atos de resistência.

Como podemos ver, a matéria intitulada Recrudesceram os distúrbios na Palestina (7/07/1936), apresenta a sub-manchete intitulada Atentado terrorista, na qual relata que a explosão de uma bomba teria ferido três judeus. Faz-se alusão à participação de civis palestinos, que o jornal novamente nomeia como árabes, na realização da explosão. E ao final da matéria se narra que as tropas britânicas foram obrigadas a usar armas de fogo contra um bando de árabes. 
Em outra matéria os árabes são cunhados, por exemplo, como agitadores terroristas (Tropas britânicas enviadas para a Palestina - Folha da Manhã - 9/10/1936). Em ambas as matérias, a justaposição do termo terrorista com as palavras agitador ou bando evidencia um olhar já fundante em relação à luta árabe: aqueles sujeitos são parte de um grupo de perturbadores da ordem que espalham terror sem justificativa.

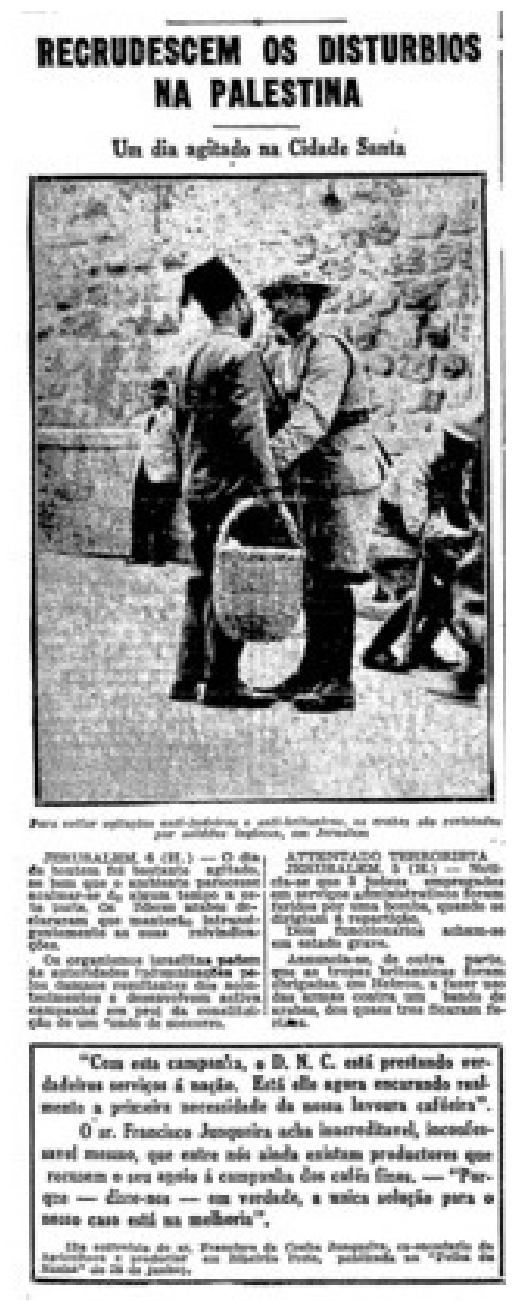

Fig.1. Matéria Recrudescem os distúrbios na Palestina cuja foto mostra um policial inglês revistando um árabe. A legenda na notícia traz a seguinte inscrição: "Para evitar agitações anti-judaicas e anti-britânicas, os árabes são revistados por soldados ingleses, em Jerusalém."

O tratamento discursivo dado aos palestinos, expondo um tom de descaso quanto às manifestações do civis e às suas lutas, incomoda a Liga Patriótica Syria que, 
através de uma carta do seu, então, secretário geral, Sr. Chafick Amad, relata a insatisfação de como estão sendo reportados, no jornal Folha da Manhã, os acontecimentos na Palestina.

Diariamente, publicam os jornais telegramas em que se fala de "atentados terroristas" praticados por "bandoleiros árabes" contra os judeus e as tropas inglesas. (...) Imagine sr. Editor-chefe, que tais "bandidos" são justamente a fina flor da mocidade árabe. Abandonando os bancos das escolas e faculdades, esses moços vão para a luta em defesa de um ideal, o maior ideal da Humanidade: a Liberdade. E, por isso, são chamados pelas agências de "bandidos", "bandoleiros" e "terroristas" (A Liga Patriotica Syria critica a maneira por que são apresentados os acontecimentos na Palestina - Folha da Manhã - 6/01/1938).

Nesse sentido, o fato de os palestinos usarem de violência, quando confrontados com a polícia britânica e as organizações paramilitares judias, é o álibi que criminaliza o árabe, representando-o de forma arbitrária, como se em meio às forças que engendram o conflito reportado a resistência palestina nada fizesse senão espalhar o terror. Percebemos, portanto, um correlação direta entre os significantes árabes e terroristas, associação amplamente difundida, nos dias atuais, pelos meios de comunicação hegemônicos.

\section{Redefinição no discurso do jornal; os terroristas, agora, são os judeus}

Em meio ao tom pró-judaico para a criação de um Estado na Palestina, que preenchia as matérias durante a década de 1940, ocorreu um contraponto, a designação dos judeus como terroristas. Passou-se a ter, nos jornais, uma preocupação em nomear, apontar a culpabilidade de um ato violento a um grupo específico, afastando-se das estratégias discursivas pela via do não dito usadas nas reportagens da década de 1930. Neste momento, as matérias continham sucintas descrições referentes aos variados grupos, denominando-os de acordo com sua periculosidade: grupo extremista Stern, grupo extremista Irgun Zval Leumi, exército paramilitar Haganá:

[...] Hoje, os terroristas judeus sequestram cinco oficiais britânicos [...] os cinco oficiais foram detidos como reféns para que possa ser exigida e libertação de dois membros da organização "Stern" - fundada por Abrahan Stern, líder terrorista judeu morto [...] A organização terrorista "Haganah" reivindica oficialmente a responsabilidade de todos os atos de sabotagem ocorridos [...] Por sua vez, a organização "Irgum" espalhou panfletos convocando o povo judeu ao combate [...] (Tropas inglesas em luta com os judeus - Folha da Manhã - 19/06/1946).

Apresenta-se, assim, no discurso jornalístico da época, uma dissonância quanto à condução da opinião pública pelo jornal Folha da Manhã. Ao mesmo tempo em que desde a década de 1920 as matérias rememoram a promessa da instauração do lar judeu 
na Palestina, o jornal prolifera as matérias que denigrem as movimentações dos grupos paramilitares judeus.

A redefinição do tratamento da palavra terrorista, que se volta, nesse momento, aos judeus, foi despertada pela publicação de um documento secreto inglês intitulado Livro Branco, em 1939. Este documento do governo britânico se ocupava de três questões: o futuro político da Palestina, a imigração judaica e a venda de terra aos judeus. Porém, limitavam os judeus nos três apontamentos, restringindo a imigração e a venda das terras aos mesmos.

Assim, ao se tornarem declaradas as estratégias políticas britânicas que estariam retardando o cumprimento do Estado judaico na Palestina foram iniciadas ações judias contra o governo britânico. A explosão do Hotel Rei Davi, onde estava instalado o Quartel General Militar Britânico e a Secretaria do Governo da Palestina, foi o ataque mais ousado da organização Irgun. Após esse ato, que culminou na morte de 91 britânicos, os jornais remeteram estritamente aos judeus a alcunha de terroristas.

Na matéria Campanha de sabotagem à violência, o jornalista descreve os ânimos da cidade três dias após o atentado e especifica que a política britânica estava no rastro dos mandantes do ato terrorista, investigando as fichas dos 100 mais perigosos terroristas de Jerusalém. Curioso observar que todos desta extensa lista eram judeus:

[...] Os bairros judeus de Jerusalém acham-se sob nervosismo crescente, enquanto soldados britânicos em patrulha novamente indicam o estado de alerta das tropas. [...] Enquanto prossegue o trabalho de revolvimento dos escombros do hotel 'Rei Davi' à procura de vítimas da explosão [...] os agentes do serviço de segurança britânico estudam fichas de cerca de uma centena dos mais desesperados terroristas da Palestina - todos líderes do 'Irgun Zvi Leumi' e do 'Bando Stern'. [...] (grifo nosso) (Campanha de sabotagem à violência- 25/07/1946).

Apesar de as notícias do ano de 1946 relatarem agitações por parte dos palestinos, não há qualquer ocorrência de um vínculo entre eles e o significante terrorista. Um tratamento que parece demonstrar, por parte das agências internacionais de notícias, o quanto elas estão dispostas a atender aos interesses britânicos. Por se tratar de um momento no qual a organização paramilitar judia, Irgun, estava efetuando atos de violência e terror contra a polícia britânica, toda a depreciação na forma discursiva recai somente sobre os judeus. Vejamos:

[...] comutou em prisão perpétua a condenação à morte de dois terroristas judeus membros da "Irgum Zvai Leumi" [...] A emissora secreta da organização terrorista semita "Irgum Zvai Leumi" divulgou a seguinte nota: "Agora que os nossos homens foram salvos, os três oficiais britânicos ainda em nossas mãos serão postos em liberdade. [...] (Comutada em prisão perpétua a pena de morte imposta pelos terroristas - Folha da Manhã - 4/07/1946). 


\section{Conclusão}

O deslizamento do termo terrorista nos faz notar o quanto a problemática da imparcialidade no discurso jornalístico é, antes de tudo, submetida aos jogos de interesses, no caso das forças imperialistas britânicas. O colamento do significante ora no árabe, ora no judeu contribui substancialmente para que o poder hegemônico estabelecido impeça que o contraste e a complexidade existentes entre as forças envolvidas se manifestem.

De forma mais ampla, esta pesquisa nos leva a considerar que nos chamados conflitos de longa duração, o reconhecimento de aspectos subjetivos e a imbricação das redes de poderes são dados fundamentais para desvelar o processo de sedimentação de significantes (terroristas, por exemplo), e portanto de produção de homogeneizações disseminadas pelas narrativas midiáticas. Neste espaço no qual sujeitos e fatos são tomados por estereotipias tão maciçamente divulgadas, a reflexão sobre suas lutas e as formas de inscrição dos poderes é que dá a ver os possíveis deslizes dos significantes a ele vinculados.

No campo dos media, parece fundamental reconhecer que o acontecimento jornalístico é uma construção tomada por elementos discursivos e culturais implicados, de forma inexorável, no quadro de produção de sentidos acerca do acontecimento propriamente dito. Para Stuart Hall,

[...] tornar um acontecimento legível é um processo social - constituído por um número de práticas jornalísticas específicas, que compreendem [...] suposições cruciais sobre o que é a sociedade e como ela funciona (1999, p. 226).

Essas suposições fazem parte de um quadro cultural - modos de ser e de saber que é determinante neste processo. Dirá ainda Hall, que

[...] Um acontecimento só 'faz sentido' se se puder colocar num âmbito de conhecidas identificações sociais e culturais. Se os jornalistas não dispusessem - mesmo de forma rotineira - de tais 'mapas' culturais do mundo social, não poderiam 'dar sentido' aos acontecimentos [...] que constituem o conteúdo básico do que é 'noticiável' (1999, p. 226).

A partir desses pressupostos, a abordagem proposta entende que, na tessitura da intriga (RICOEUR, 2010), reconhecer as marcas dos mapas culturais é não só dar a ver o processo de produção de sentidos acerca do acontecimento, mas também compreender as formas de inscrição das dicotomias e estereotipias no âmbito dos conflitos de que se fala.

E mais, ela também entende que fazer sentido (o que na fala de Hall pressupõe aquele que lê) e dar sentido (tarefa daquele que tece a intriga: o jornalista) são processos imbricados no próprio jogo da configuração narrativa. É Ricoeur quem nos lembra que "o acontecimento completo é não apenas que alguém tome a palavra e dirija-se 
a um interlocutor, é também que ambicione levar à linguagem e partilhar com outro uma nova experiência". (RICOEUR, 2010, p.199).

E sob essa ótica, é a narração do conflito, portanto os modos de torná-lo presente, que evidencia não só as possíveis verdades que neste conflito se encerram, como também o próprio jogo de poder que se inscreve naquele acontecimento. As análises feitas ressaltam que narrar este conflito não é jamais um gesto que se queira pensar objetivo, neutro ou imparcial. Ele é infinitamente mais complexo; requer o reconhecimento de lutas travadas no âmbito do jornalismo, de suas narrativas e, fundamentalmente, no espaço geográfico no qual e a partir do qual esses narrares são produzidos.

Na perspectiva do território palestino, o desafio é imenso. Diante do esforço, por parte de forças hegemônicas, de destruir e apagar aquele território,

\section{[...] é preciso seguir contando histórias [da Palestina] de forma contundente e tão insistentemente, e de tantos modos quantos forem possíveis, para chamarmos atenção, pois sempre há o medo de que a Palestina possa desaparecer. (SAID, 2003, p.187; tradução livre)}

Sendo assim, como pode/deve o jornalismo atuar naquele espaço onde o ato de narrar é entendido como um gesto de resistência? Esta reflexão quer sugerir que deparar-se com este desafio é também discutir, no âmbito do jornalismo, a ideia de que as relações de poder inscritas em um determinado acontecimento se tornam mais evidentes na medida em que se reconhece como os modos de fala colocam em cena as disputas por hegemonias. E é por este viés que o conflito - qualquer que seja - deixa de ser somente o conteúdo da narrativa, passando também a existir a partir da forma e dos modos de que dele se fala. De acordo com Benetti, o

acontecimento jornalístico está inserido em uma ordem hermenêutica, ou ordem dos sentidos, de grande complexidade - não apenas pelos procedimentos exigidos para que um fenômeno se transforme em acontecimento, mas também pelos quadros de referência que ajuda a legitimar (2010, p.149).

É sob essa ótica que esta pesquisa tem avançado e contribuído para que, no âmbito do jornalismo, se possa entender que narrar o conflito Israel/Palestina é narrar as lutas que se inscrevem e se instalam no próprio conflito. São essas lutas e as formas de inscrição dos poderes que dão a ver os possíveis significados do conflito, aspectos cruciais que o fazem ser, portanto, um acontecimento jornalístico.

Fernando Antônio Resende é vice-coordenador e professor do Pós-Graduação em Comunicação do Departamento de Mídia e Estudos Culturais da UFF e coordenador local 
do Erasmus Mundus Joint Doctorate - Cultural Studies in Literary Interzones (UFF/Bergamo/Tübingen/Perpignan/ Delhi). É pesquisador PQ/CNPq. É doutor em Ciências da Comunicação pela USP e pós-doutor na School of Oriental and African Studies (SOAS - University of London - Inglaterra).

fernandoaresende1501@gmail.com

Letícia Rafaela Rossignoli é doutoranda no PPGCOM da UFF. letrossignoli@gmail.com

\section{Referências}

BENETTI, M. O jornalismo como acontecimento. In: BENETTI M; FONSECA, V. (orgs.). Jornalismo e acontecimento: mapeamentos críticos. V. 1. Florianópolis: Insular, 2010.

FINKELSTEIN, N. Imagem e realidade do conflito Israel-Palestina. Rio de Janeiro: Record, 2005.

HALL, S. A produção social das notícias: o mugging nos media. In: TRAQUINA, N. (Org.). Jornalismo: questões, teorias e 'estórias'. Lisboa: Vega, 1999.

KELLNER, D. Cultura da mídia. Bauru, EDUSC, 2001.

MATAR, D. \& HARB, Z. (eds.). Narrating conflict in the Middle East: discourse, image and communications practices in Lebanon and Palestine. London: I B Tauris, 2013.

MORAES, D. A batalha da mídia: governos progressistas e políticas de comunicação na América Latina e outros ensaios. 1. ed. Rio de Janeiro: Pão e Rosas, 2009. v. 1. 272p .

NATALI, J. B. Jornalismo Internacional. São Paulo: Contexto, 2004.

ORLANDI, E. L. P. Análise de discurso: princípios e procedimentos (1º. Edição: 1990, Ed. Pontes). $2^{\circ}$. Ed. Campinas: Pontes, 2007.

RESENDE, F. Às desordens e aos sentidos: a narrativa como problema de pesquisa. In: SILVA, G., KÜNSCH, D., BERGER, C. e ALBUQUERQUE, A. (orgs.). Jornalismo contemporâneo - figurações, impasses e perspectivas. Salvador: Edufba, 2011/a, p. 119-138.

RICOEUR, P. Tempo e narrativa. (Tomos 1, 2 e 3). São Paulo: Martins Fontes, 2010.

ROGOFF, I. Terra Infirma: geography's visual culture. London: Routledge, 2000.

SAID, E. A questão da Palestina. São Paulo: Unesp, 2011.

SODRÉ, N. W. História da Imprensa no Brasil. São Paulo: Mauad, 1999.

VICENZI, R. A. N, Nacionalismo árabe: apogeu e declínio. 220 f, Tese (doutorado em Ciência Política - Faculdade de Filosofia, Letras e Ciências Humanas, Universidade de São Paulo). São Paulo, 2006. 